\title{
LIFE CYCLE EXTENSION OF A PAVEMENT STRUCTURE
}

The pavement structure, namely pavement surfacing must meet the criteria required to provide operational service during the whole life cycle of the pavement. Surfacing design composed of layer strengths and proposed materials is defined by design method which calculates the stress state during long-term transport and environmental conditions. The designed surfacing life cycle is defined in respect to traffic load acting on the pavement and road class for a period of about 20 years. Given the practical aspects of road administration, pavement reconstruction is usually due only at the end of the life cycle, when the original materials are replaced by new materials and the layer strength is re-evaluated. Since the overall life cycle of the whole pavement is significantly longer than that of the surfacing, it is necessary to consider possibilities to extend the life cycle of the surfacing either through various technologies, i.e. reinforcement, overlays or recycling. Timing of execution of such action plays a paramount role, and it has impacts on future financial flows of road administrator as well as economic aspects of transportation for the whole society. This paper describes analytical calculations and experimental measurements of surfacing materials, as well as accelerated pavement testing process needed for ascertainment of operational performance of a pavement construction during its life cycle. Finally, a case study encompassing the whole method is presented.

Keywords: Pavement management system, life cycle extension, pavement surfacing, accelerated pavement testing.

\section{Introduction}

Life cycle of a pavement surfacing should be modelled in advance of a pavement construction and it should be a corner stone of a successful long term administration of given road section. Design and evaluation of pavement surfacing rehabilitation in the framework of the life cycle requires a combination of analytical and computational models, and experimental measurements on sections which are subject to traffic loading in real-life operation. In the analytical part, methods are proposed to calculate the design of the pavement construction, fatigue characteristics are defined as trend lines of asphalt material surfacing life-expectancy, computation models are defined for calculation of the life cycle and economic efficiency of all proposed variants. Experimental part consists of an experiment to determine the basic material and fatigue characteristics and deformation trend lines.

Life Cycle of surfacing materials in the pavement construction is defined through the analytical calculation method of pavement construction, where life expectancy is derived through the fatigue characteristics of materials used. However, the surfacing life cycle itself can be defined by other means than fatigue characteristics, for instance, permanent deformation expressed through pavement unevenness, foremost rutting (transverse unevenness).

Based on surfacing life cycle defined through the material fatigue and permanent deformation expressed by unevenness, it is possible to design rehabilitation variant - recycling or overlay at different times within the life cycle. These variants extend the original life cycle. In terms of efficiency, variants of the rehabilitation are evaluated by means of Cost Benefit Analysis (CBA) and mathematical optimisation model.

\section{Experimental Pavement Model}

Experimental pavement section was built on 1:1 scale, on which heavy truck axle acted as a simulated traffic load prescribed as equivalent single axle load, this is called accelerated pavement testing (APT). The general principle of APT testing is to apply artificially inducted load similar to real life traffic load in a compressed time period, thus providing an expedited means of evaluating factors associated with traffic-pavement interaction. APT is essentially a full-scale laboratory test during which loaded truck wheels are used to traffic sections of full-scale road pavement constructed using conventional techniques.

In order to define surfacing lifecycle in the pavement construction and the application of technological variants of rehabilitation, a standard pavement type usual for a primary road was designed. The pavement was designed according to standard methodology [1] for a minimum level of traffic load - $2 \times 10^{6}$ design axles. The pavement design of built experimental pavement

\footnotetext{
* Jan Mikolaj, Lubos Remek, Matus Kozel

Faculty of Civil Engineering, University of Zilina, Slovakia

E-mail: jan.mikolaj@fstav.uniza.sk
} 
section is shown in Fig. 1. Subgrade is simulated by a rubber layer on concrete with equivalent modulus of $\mathrm{E}_{\text {def }} 100 \mathrm{MPa}$. The complete APT tester is shown in Fig. 2. It is a Semi-mobile linear APT facility with axle load of $57.5 \mathrm{kN}$ moving at $2.22 \mathrm{~m} \cdot \mathrm{s}^{-1}$.
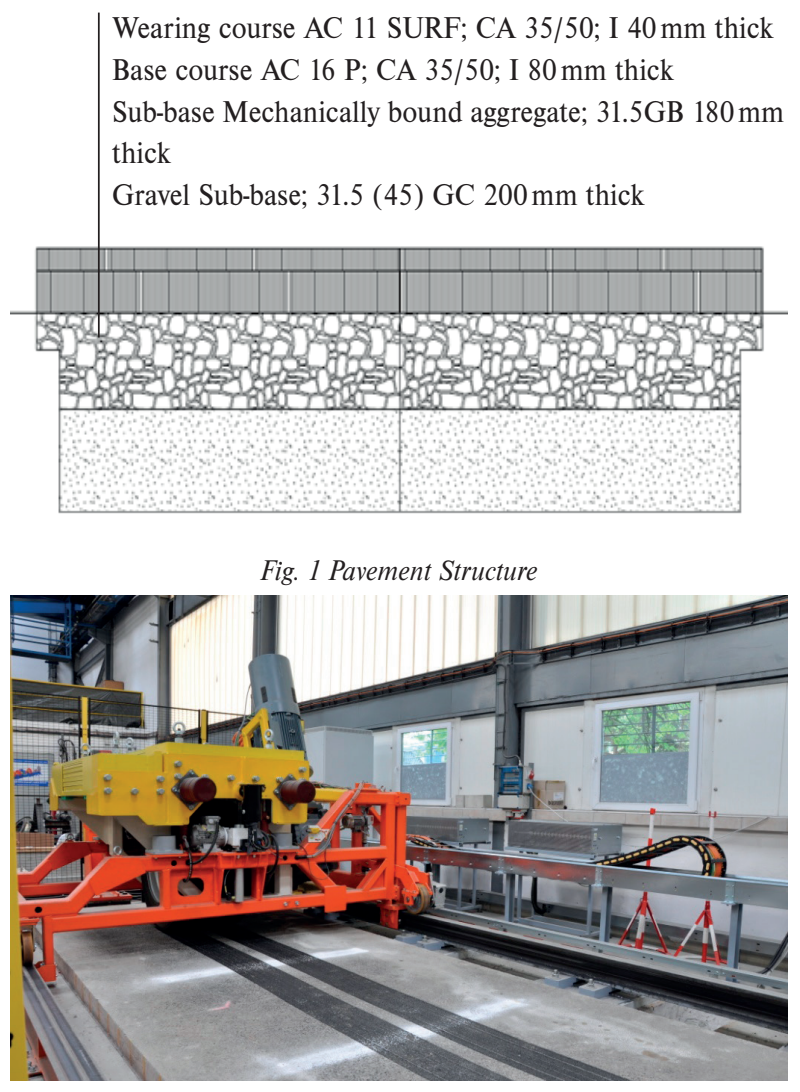

Fig. 2 APT tester
Pavement structure layers are designed from generic materials defined in national standards. Table 1 contains material characteristics ascertained by the initial physical-measurement of surfacing materials. Two point bending test was used for this purpose. These values fall within the required interval for this particular type of pavement.

\section{Asphalt Concrete Material Layer}

\subsection{Complex stiffness modulus}

Measurement of complex stiffness modulus of a surfacing layer in the pavement structure was carried out according to national standard which is in compliance with European Union Standards [2]. Measurement of the complex stiffness modulus is performed with utilisation of short-term alternating harmonic load. It expresses the proportion of the maximum amplitudes of excitation tension and deformation induced by it and their phase shift. On the basis of measurements performed for different

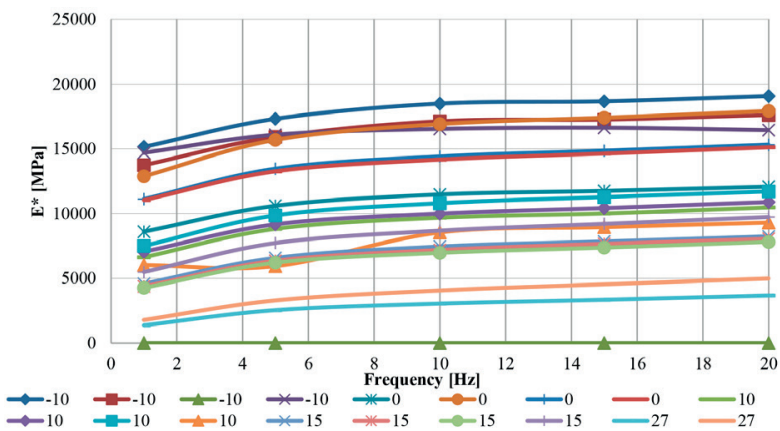

Fig. $3 E^{*}$ relation to frequency and temperature

Table 1

Material Characteristics of Pavement Layers

\begin{tabular}{|c|c|c|c|c|c|}
\hline Layer & Complex modulus & & Strength & Poisson number & Layer Thickness \\
\hline AC 11 SURF & $10891 \mathrm{MPa}$ & & $3.2 \mathrm{MPa}$ & 0.3 & $40 \mathrm{~mm}$ \\
\hline AC $16 \mathrm{P}$ & $8317 \mathrm{MPa}$ & & 2.4 MPa & 0.33 & $80 \mathrm{~mm}$ \\
\hline MBA, 31.5 GB & $586 \mathrm{MPa}$ & & $0.1 \mathrm{MPa}$ & 0.25 & $180 \mathrm{~mm}$ \\
\hline Gravel Sub-base, 31.5 & $365 \mathrm{MPa}$ & & $0.07 \mathrm{MPa}$ & 0.3 & $200 \mathrm{~mm}$ \\
\hline Sub-grade & $100 \mathrm{MPa}$ & & - & 0.3 & - \\
\hline Complex modulus of $\mathrm{AC}$ & sured at different fre & ncies & & & Table 2 \\
\hline \multirow{3}{*}{ Temperature ${ }^{\circ} \mathrm{C}$} & \multicolumn{5}{|c|}{$\mathrm{E}^{*}[\mathrm{MPa}]$} \\
\hline & \multicolumn{5}{|c|}{ Frequency $\mathrm{Hz}$} \\
\hline & 1 & 5 & & 15 & 20 \\
\hline-10 & 14532 & 16449 & & 17524 & 17715 \\
\hline 0 & 10919 & 13261 & & 14664 & 15112 \\
\hline 10 & 7060 & 9171 & & 10430 & 10891 \\
\hline 15 & 4686 & 6721 & & 8026 & 8463 \\
\hline 27 & 1581 & 2919 & & 3944 & 4334 \\
\hline
\end{tabular}


temperature values ascertained are presented in Table 2 and Fig. 3.

\subsection{Sub-base Layers}

The measured values on sub-base layers are performed using an LDD and Clegg that, after conversion based on the equation (1) according to [3], were adjusted to CBR (California Bearing Ratio) values. The results are shown in chart in Fig. 4.

$C B R_{\text {STN721016 }}=0.78 * C I V^{1.12}$

Where:

CIV - Clegg impact value.

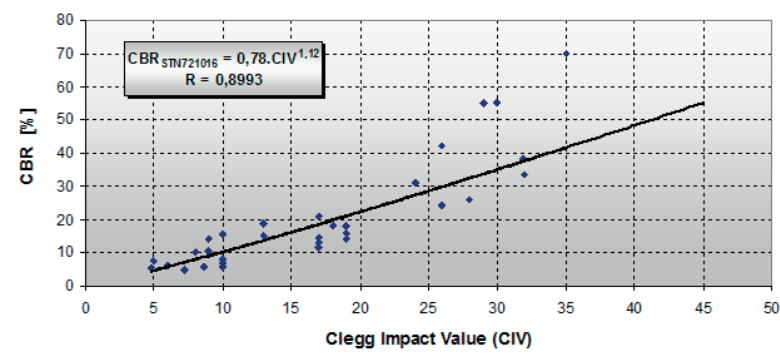

Fig. 4 Clegg and CBR Relationship

Subsequently, the CBR values were converted according to equation (2) [4] to $\left(E_{N}\right)$ value with the use of following formula:

$E_{N}=17.6 * C B R^{0.64}$

\subsection{Fatigue Characteristics}

Fatigue characteristics are used in the assessment of pavement resilience against repeated loading. Test temperature for the endurance test is $10^{\circ} \mathrm{C}$ and the frequency of cyclic loading is 25 $\mathrm{Hz}$. The test is carried out at a constant bend of the test sample

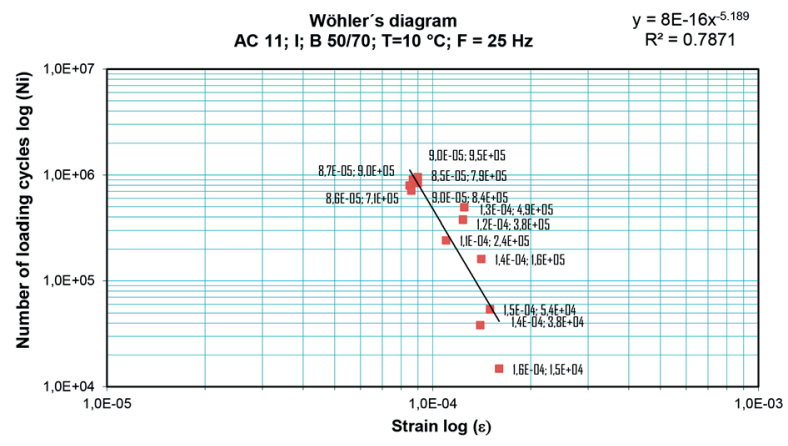

Fig. 5 Wohler diagram for AC 11 SURF during the test. Fatigue tests were carried out according to the European standard [5].

The results of research [6] carried out in the ambit of fatigue characteristics are presented in Fig. 5 and Table 3.

Values of fatigue parameters for mix AC 11 SURF

Table 3

\begin{tabular}{ccccc}
\hline Parameter & $a$ & $1 / b$ & $\varepsilon_{{ }_{6}} 10^{6}$ & $r^{2}$ \\
\hline Fatigue parameters & -15.0754 & -0.1927 & 86.77 & 0.7871 \\
\hline
\end{tabular}

\section{Ascertainment of the Life Cycle}

The life cycle of a surfacing layer can be defined through the means of bearing capacity evaluation on the basis of the stress and fatigue characteristics up until the point of a breakdown. In addition, however, the ACM (Asphalt Concrete Material) is subject to permanent deformation as a result of traffic loading, which may cause the loss of operational capability defined by the standard prior to its failure caused by fatigue. These deformations manifest as plastic deformations.

\subsection{Bearing Capacity}

Calculation of the life cycle is possible on the basis of the calculation method for the design of pavement structure [7 and 1]. This method imposes structural value for the surfacing layers which is expressed by comparing the calculated radial stress on the bottom of the considered layer with the strength in the same layer. That in view of the repeated loading is reduced by a fatigue factor $\mathrm{S}_{\mathrm{N}}$.

$S V \geq \frac{\sigma_{r i}}{S N * R_{i}}$

Where:

$S V$ - structural value

$\sigma_{r i}$ - radial stress,

$R_{i}$ - strength,

$S N$ - fatigue characteristic.

The calculated radial stress in the surfacing layer is calculated on the basis of the thickness of the layers, complex modulus and Poisson number by means of calculation in the layered elastic half space model [8]. Calculated stress $\left(\sigma_{\mathrm{ri}}\right)$ is based on the effects of repeated loading, which is expressed in terms of the design axle load with the axle weight of 10 tonnes $(2 \mathrm{P}=100 \mathrm{kN})$. Behaviour and properties of the materials used in the pavement construction pertain to certain climatic conditions, therefore under standard processes three different periods are considered during which the resiliency and elastic modulus change. In our case, the modelling of the pavement construction behaviour happens in constant conditions persisting in laboratory where the 
experimental pavement section is built. These constitute medium conditions, i.e. constant temperature above $+10{ }^{\circ} \mathrm{C}$.

Fatigue characteristic $\left(\mathrm{S}_{\mathrm{N}}\right)$ is expressed via parameters (a) and (b) which represent the shape of the Wohler curve and the expected traffic load $(\mathrm{N})$.

$S_{N}=a-b * \log N_{c}$

where:

$\mathrm{a}, \mathrm{b}$ - fatigue characteristics.

On the basis of fatigue characteristic measurements (chapter 3.1) for AC 11 SURF mixture, the values of fatigue coefficients $a, b$ are:

$\mathrm{a}=1, \mathrm{~b}=0.11$

The life cycle of ACM in the pavement construction can be expressed through the equation (1), on the basis of the stress calculation in pavement construction, strength and fatigue characteristics. The Structural Value must be less than 1, in order for the stress not to exceed the resiliency value. If it is exceeded, the surfacing layer is at the end of their useful life and collapses. The length of life cycle therefore defines stress in the surfacing layer and a decrease of strength depending on the traffic load expressed by the fatigue characteristics. For this reason, stress calculations were made for the pavement construction and its characteristics for the duration of the whole life cycle. In Table 4, stress values are listed in various stages of the life cycle depending on the number of loads and complex modules, whose values also decrease depending on the repeated loading.

The life-cycle itself, expressed by utilisation of Structural values in accordance with equation 1 is shown in Fig. 6 . Calculations show that the life cycle of a surfacing in the testing pavement section is defined by 7.5 million of design axle passes. In this case, the annual traffic load will be max. 375000 design axle loads, which, for given traffic intensity, equals to life expectancy of 20 years.

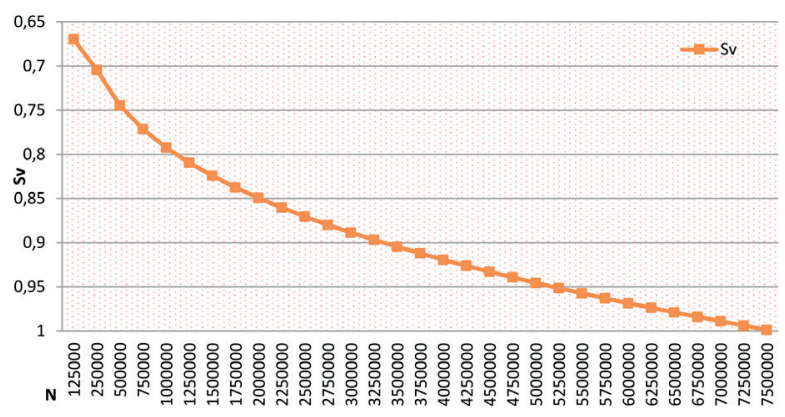

Fig. 6 Life cycle of surfacing in the pavement construction depending on the number of loading cycles

\subsection{Permanent Deformation}

Permanent deformations are induced by traffic loading and external environmental conditions such as temperature, humidity, radiation, etc. The material deteriorates to a point where it is no longer suitable from the viewpoint of operational characteristics, and thus ends its life cycle [9]. In contrast to fatigue and its relation to the residual life expectancy, which can be expressed by different coefficients [10], e.g. this can not be done for permanent deformation. It is foremost because of the fact that surfacing layer is, during deformation, neither in elastic nor in plastic state and the calculations are extremely sensitive to variety of conditions from the external environment. Therefore, experimental measurements are used to record pavement shape changes, and, by means of mathematical models environmental conditions are directly derived [11, 12 and 13]. In our research, deformation characteristics were obtained through measurements on the experimental pavement section after 50, 100 and 150 thousand loads. Deformations are shown in Fig. 7. Trend line of deformation in relation to load was derived and it is shown in Fig. 8.

Radial Stress and strength resiliency values in ACM layers based on $\mathrm{Ni}$

Table 4

\begin{tabular}{cccccc}
\hline The number of Ni & 0 & $1.5 \times 10^{\wedge} 6$ & $3 \times 10^{\wedge} 6$ & $4.5 \times 10^{\wedge} 6$ & $6 \times 10^{\wedge} 6$ \\
\hline $\begin{array}{c}\text { AC 11 SURF } \\
\mathbf{E}^{*}(\mathrm{MPa})\end{array}$ & 10891 & 5998 & 5759 & 5620 & 5521 \\
\hline $\begin{array}{c}\text { AC 16 P } \\
\mathbf{E}^{*}(\mathbf{M P a})\end{array}$ & 8317 & 4580 & 4398 & 4291 & 4216 \\
\hline $\begin{array}{c}\text { Stress } \\
(\mathbf{M P a})\end{array}$ & 0.978132 & 0.634328 & 0.613133 & 0.600401 & 0.591348 \\
\hline $\begin{array}{c}\text { Strength } \\
(\mathrm{MPa})\end{array}$ & 2.4 & 0.769512 & 0.690040 & 0.643552 & 0.584278 \\
\hline
\end{tabular}




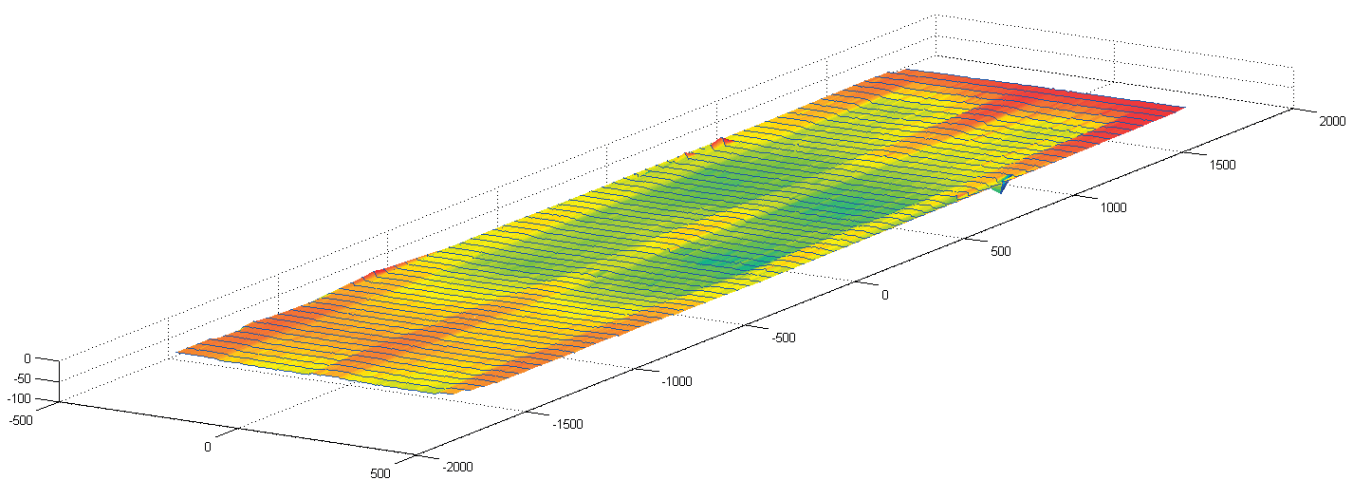

Fig. 7 Life cycle of surfacing in the pavement construction depending on the number of loading cycles - permanent deformations

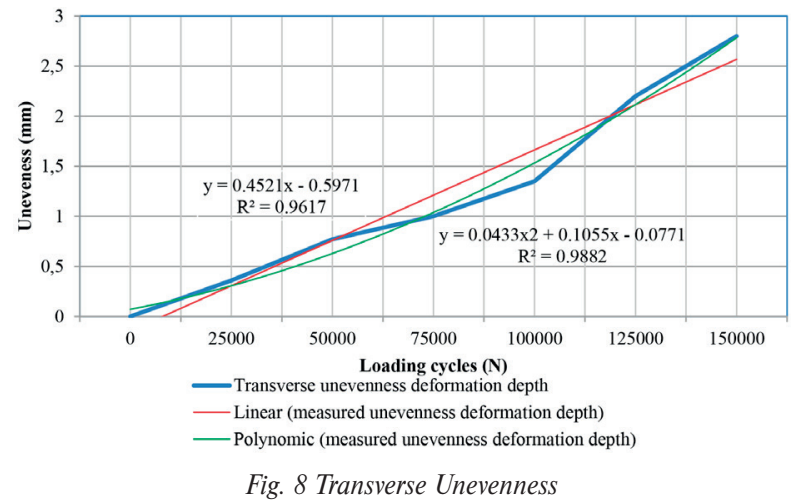

Stress Calculations Before and After Rehabilitation

\begin{tabular}{|c|c|c|c|c|c|c|c|c|}
\hline year & 5 & 10 & 15 & 20 & 25 & 30 & 35 & 40 \\
\hline $\begin{array}{l}\text { ACM layer thickness } \\
\text { increase }(\mathrm{mm})\end{array}$ & 36 & 52 & 62 & 71 & - & - & - & - \\
\hline 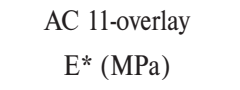 & 10891 & 10891 & 10891 & 10891 & 5445 & 5445 & 5445 & 5445 \\
\hline $\begin{array}{l}\text { AC } 11 \text { SURF E* } \\
\text { (MPa) }\end{array}$ & 5945 & 5682 & 5551 & 5445 & 5354 & 5304 & 5248 & 5205 \\
\hline AC 16 P E* $^{*}(\mathrm{MPa})$ & 4540 & 4339 & 4239 & 4158 & 4088 & 4051 & 4008 & 3975 \\
\hline $\begin{array}{c}\text { Stress prior to } \\
\text { rehabilitation }(\mathrm{MPa})\end{array}$ & 0.751838 & 0.664456 & 0.620544 & 0.584984 & 0.48615 & 0.4465 & 0.42012 & 0.40146 \\
\hline $\begin{array}{c}\text { Stress prior to } \\
\text { rehabilitation }(\mathrm{MPa})\end{array}$ & 0.508571 & 0.464004 & 0.429907 & 0.40146 & 0.477312 & 0.428528 & 0.404145 & 0.382118 \\
\hline
\end{tabular}

\section{Extension of the Life Cycle}

The life cycle represents number of load repetitions acting on surfacing layer up to the state of a breakdown. For economic reasons, however, it may not be the cheapest or most efficient to wait until the very end of the surfacing life cycle, rehabilitation at earlier date may be more efficient. In our case, the rehabilitation of surfacing denotes improvements by means of overlay or mill \& replace action, which restores the original properties of surfacing layer thus shifts the layer to the beginning of its life cycle [14]. This extends the life cycle of up to 20 years. In terms of analytical computational structural method, the rehabilitation manifests itself by increased complex modulus of surfacing layer and by adjusted thickness of the layer i. In Table 5, proposed rehabilitation is shown for three time periods of the life cycle 
- rehabilitation performed in year 5, 10, 15 and rehabilitation at the end of the initial life cycle in year 20. Thus there are four scenarios: Rehabilitation in $5^{\text {th }}$ year, Rehabilitation in $10^{\text {th }}$ year, Rehabilitation in $15^{\text {th }}$ year and Rehabilitation in $20^{\text {th }}$ year. The rehabilitation design constitutes various increase of surfacing thicknesses (without milling) in relation to current state of the surfacing material based on analytical calculation method [1]. The elastic modulus of surfacing layer is shown for each rehabilitation action year and the calculated stress before and after rehabilitation. Rehabilitation design in thickness increase (millimetres), rehabilitation year and extension of life expectancy are shown in Table 5. Graphically, individual variants of extended life in different years are shown in Fig. 9.

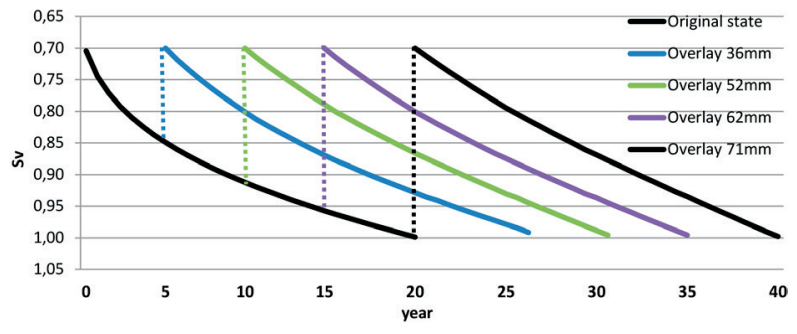

Fig. 9 Rehabilitation Design at Various Stages of the Life Cycle

\section{Societal aspects and economic efficiency}

The aim is to select rehabilitation variant and year which maximises economic efficiency, i.e. generates the most value for money. For calculation of economic efficiency, rehabilitation costs, increased maintenance costs and increased user costs have to be considered in case of postponed rehabilitation or for variant without any rehabilitation. Maintenance and user costs increase proportionally during the entire life cycle with operational capability of the pavement surface. The optimal time of rehabilitation can be calculated with the use of Cost Benefit Analysis in which the extension of the original life and related maintenance and user costs are taken into account. Optimisation is a mathematical relationship including all costs and surfacing layer operation.

The economic efficiency analysis is carried out with the use of Cost-Benefit Analysis (CBA). CBA evaluates positive impacts - benefits - related to improved operational parameters of the pavement in comparison to costs for applied rehabilitation actions. The Payback Period (PP), Internal Rate of Return (IRR) and Net Present Value (NPV) are economic indicators of CBA.

Calculation of economic efficiency for the experimental pavement section was performed on the basis of rehabilitation, maintenance and user costs for different variants according to Fig. 9. Quantification of road user costs was made for arterial road with usual traffic flow with yearly equivalent axle loads described in the previous chapters. The results are shown in Table 6. Rehabilitation costs are market averages, and user costs were quantified with the use of HDM-4 ( Highway Development and Management Software) endorsed by the World Bank.

For quantification of user costs, vehicle fleet composed from personal car Skoda Octavia 1.6 TDI, light utility vehicle Fiat Ducato, medium truck Iveco Eurocargo, heavy truck Volovo FM9, articulated truck Volvo FH 12 + trailer Schwartzmuller and Bus Karosa C956. Their technical and economical parameters (unit

The results of the rehabilitation, maintenance and user costs

Table 6

\begin{tabular}{|c|c|c|c|c|c|c|}
\hline \multicolumn{2}{|l|}{ Variant } & Variant Scenario & $\begin{array}{c}\text { Rehabilitation } \\
\text { year }\end{array}$ & $\begin{array}{l}\text { Rehabilitation } 10^{\text {th }} \\
\text { year }\end{array}$ & $\begin{array}{l}\text { Rehabilitation } 15^{\text {th }} \\
\text { year }\end{array}$ & $\begin{array}{c}\text { Rehabilitation } 20^{\text {th }} \\
\text { year }\end{array}$ \\
\hline \multirow{2}{*}{\multicolumn{2}{|c|}{ Rehabilitation Action }} & \multirow{2}{*}{-} & Overlay & Overlay & Overlay & Overlay \\
\hline & & & $36 \mathrm{~mm}$ & $52 \mathrm{~mm}$ & $62 \mathrm{~mm}$ & $71 \mathrm{~mm}$ \\
\hline \multicolumn{2}{|l|}{ Investment Cost } & 0 & 69084 & 99788 & 118978 & 136249 \\
\hline \multicolumn{2}{|l|}{ Maintenance Cost } & 846938 & 858066 & 941350 & 1162456 & 1581330 \\
\hline \multicolumn{2}{|l|}{ Road Agency Cost } & 846938 & 927150 & 1041138 & 1281434 & 1717579 \\
\hline \multirow{3}{*}{ Road User Costs } & $\begin{array}{l}\text { Vehicle Operating } \\
\text { Cost }\end{array}$ & 8316431 & 9995382 & 11689165 & 13594956 & 16045362 \\
\hline & Travel Time Cost & 822241 & 973891 & 1125826 & 1290801 & 1569194 \\
\hline & $\begin{array}{l}\text { Total Road User } \\
\text { Cost }\end{array}$ & 9138673 & 10969273 & 12814991 & 14885757 & 17614555 \\
\hline \multicolumn{2}{|l|}{ Life Cycle Length } & 20 & 25 & 30 & 35 & 40 \\
\hline \multicolumn{2}{|l|}{ Optimisation index } & 0 & 475857 & 461871 & 461920 & 483303 \\
\hline \multirow{3}{*}{ CBA } & NPV & - & 20333 & 26739 & 14527 & 1438 \\
\hline & IRR & - & $48.30 \%$ & $155.10 \%$ & $139.40 \%$ & $99.50 \%$ \\
\hline & PP & - & 6 & 11 & 15 & 20 \\
\hline
\end{tabular}


cost) were predefined in the HDM-4 calibration file for Slovak republic (unit cost were adjusted for year 2016). Vehicle travel speed was computed in the HDM-4 software, the road section was of average curvature ( $\left.15 \mathrm{deg} \cdot \mathrm{km}^{-1}\right)$ and level $\left(2 \mathrm{~m} \cdot \mathrm{km}^{-1}\right)$. Speed limit was set to $90 \mathrm{~km} \cdot \mathrm{h}^{-1}$. Vehicle operation costs and Travel time costs were subsequently calculate based on this imput. Accident cost were excluded from the computation since accident class of the road section wasn't influenced by the rehabilitation.

\section{Conclusion}

This paper describes topical issues of rehabilitation magnitude selection and timing of rehabilitation to ensure life cycle extension of pavement surfacing with consideration to economic efficiency of this process. The methods described in this article are based on analytical computation methods and actual measurements on experimental pavement section with the use of accelerated pavement testing. These methods are used to defined life cycle and ascertain how different rehabilitation technologies performed in different periods of the life cycle, this can be evaluated when modelling life cycle extension of the pavement surfacing. The aim of presented calculations and experiments is the search for optimal technology and time of rehabilitation, i.e., identification of methods to extend the life cycle for the lowest sum of economic costs. The calculations of surfacing life cycle and its extensions which are presented in this article are exemplificative, yet applicable in real life conditions. Values that are necessary to measure during pavement operation are derived from experimental pavement model. Economic calculations are made using common methods with the computation model of the World Bank.

\section{Acknowledgement}

The research is supported by the European Regional Development Fund and the Slovak state budget for the project "Research Centre of University of Zilina”, ITMS 26220220183.

\section{References}

[1] GSCHWENDT, I.: Pavement Structure Design. Technical Standards 3/2009.Ministry of transport and telecommunication, Slovakia, p.52

[2] EUROPEAN COMMITTEE FOR STANDARDIZATION (CEN) EN 12697-26: Bituminous mixtures - Test method for hot mix asphalt - Part 26: Complex modulus, Brussels, Belgium 2003.

[3] ZGUTOVA, K.: Non-destructive Determining CBR Values of Ground Structures of Engineering Constructions, $14^{\text {th }}$ Intern. Multidisciplinary Scientific GeoConference SGEM 2014.

[4] MINISTRY OF TRANSPORTAION OF CZECH REPUBLIC, Czech Pavement Design Manual, TP 170, VUT Brno, CVUT: Praha: SSZ: ODS, November 2004

[5] EUROPEAN COMMITTEE FOR STANDARDIZATION (CEN): EN 12697-24: Bituminous mixtures - Test method for hot mix asphalt - Part 24: Resistant to fatigue, Brussels 2003.

[6] SCHLOSSER, F., SRAMEKOVA, E., SRAMEK, J.: Rheology, Deformational Properties and Fatigue of the Asphalt Mixtures. Advanced Materials Research, vols. 875-877, 2014, ISSN 1662-8985 (web), ISSN 1022-6680 (print), pp. 578-583, 2014.

[7] CELKO, J., KOMACKA, J.: Analysis of the Pavement Bearing Capacity on the Deflection Bowl Basis. Fifth Intern. Conference on the Bearing Capacity of Roads and Airfields, Trondheim, vol. I, pp. 609-617, 1998.

[8] NOVOTNY, B., HANUSKA, A.: The Theory of Multi Layered Half Space, Veda : Bratislava, 1983.

[9] KATMAN, H., Y., et al: Evaluation of Permanent Deformation of Unmodified and Rubber-Reinforced SMA Asphalt Mixtures Using Dynamic Creep Test, Materials Science and Engineering, vol. 2015, Hindavi Publishing Corporation, ISSN 1687-8442 online, ISSN 1687-8434- print, 2015.

[10] MINISTRY OF TRANSPORTAION OF CZECH REPUBLIC, Czech Pavement Design Manual, TP 170, VUT Brno, CVUT: Praha: SSZ: ODS, November 2004

[11] CELKO, J., DECKY, M., KOVAC, M.: An Analysis of Vehicle - Road Surface Interaction for Classification of IRI in Frame of Slovak PMS. Maintenance and Reliability. Polish Maintenance society, No. 1, 41, pp. 15-21, ISSN 1507-2711, 2009.

[12] CHYTCAKOVA, A.: Evaluation Parameters of Operational Competence in the Pavement Management System. PhD thesis, University of Zilina, November 2014.

[13] WORLD ROAD ASSOCIATION (PIARC): Highway Performance Monitoring Systems. Technical Committee 6 road management. ISBN 2-84060-052-8, p. 68, 1997.

[14] PENG, G., F., et al.: Mechanical Properties of Recycled Aggregate Concrete at Low and High Water/Binder Ratios, Materials Science and Engineering, vol. 2013, Hindavi Publishing Corporation, ISSN 1687-8442 - online, ISSN 1687-8434- print, 2013. 